\title{
The relationship between the production and construction sector and continuous professional training
}

\author{
Elena Pesotskaya ${ }^{1, *}$, Larisa Selyutina $^{2}$, Maria Ivanova $^{3}$, and Olga Egorova $^{4}$ \\ ${ }^{1}$ Saint Petersburg State University of Economics, 191023, St. Petersburg, Russia \\ ${ }^{2}$ Emperor Alexander I St. Petersburg State Transport University, 190031, St. Petersburg, Russia \\ ${ }^{3}$ Saint Petersburg State University of Civil Aviation, 196210, St. Petersburg, Russia \\ ${ }^{4}$ Mikhailovskaya Artillery Military Academy, 195009, St. Petersburg, Russia
}

\begin{abstract}
The article reveals the economic nature of the relationship between the production and construction process and continuous professional training, as well as the methods of their use in practice - in effective management decisions formation. Special emphasis is placed on the role of continuous professional training in providing the production and construction sector with specialists of the required qualification level. The possibilities of monitoring continuous professional training and its parametric range are analyzed. The universality of methodology and tools for managing continuous professional training is noted in the presence of a number of features that reflect the mechanisms of the construction industry functioning.
\end{abstract}

\section{Introduction}

The effective functioning of the production and construction sector, which has developed in the economic complex of the Russian Federation with its differentiation by regional levels, is associated with the need to solve a number of complex management problems. Among the priority tasks is the provision of construction production with a cadre of specialists whose skill level meets not only the needs of modern construction production, but also the needs of future periods - initiated by the planned growth and qualitative improvement of production and construction process [1-3].

It seems obvious that the development of production and construction activities and the development of a personnel training system for the construction industry can be carried out only in conditions of their articulation, when the reform aspirations in construction are fully supported by systematic measures in the field of its staffing. The leading role in the totality of such events belongs to the system of continuous professional training (CPT), created in Russia, tested in a number of industries and economic areas and demonstrating significant results [4-6].

The purpose of the work is to study the genetic foundations and methods of forming the relationships between the production and construction sector and continuous professional

\footnotetext{
*Corresponding author: epes2@mail.ru
} 
training, which supports and develops the qualifications of specialists in the construction profile.

\section{Materials and Methods}

Continuous professional training is characterized by systemic features, which makes it possible to unambiguously identify it as a system (more precisely, a subsystem in a higherlevel system - the national education system). This system, like any socio-economic system functioning within the economic complex of the country, is structured by industry.

In each industry or economic sphere, following the management methodology, a kind of order is formed for the professional and qualification characteristics of the specialists involved in them, for the totality of knowledge and skills that they must possess and acquire in a continuous mode, striving not only for their replenishment and development, but and updating.

CPT in the manufacturing and construction sector relies on a unified and completely stable methodology of lifelong learning, in the absence of any contradictions, but in the presence of a number of features, which in their overwhelming majority are of a realization nature.

Methodology CPT proceeds from the identification of its socio-economic essence, which was reflected in the works of a number of authors [7-9], who placed the focus of research interest as scientific, theoretical and methodological foundations CPT, and its methodological aspects. When characterizing CPT one can take as a basis the definition formulated in work [8], where it is considered as a systemically organized process of education of people throughout their working life, the need for which is due to a consistent change in working conditions associated with the emergence of new or additional professional requirements. Taking these requirements into account and adapting to them provides support for the competitiveness of workers in the domestic and foreign labor markets.

\section{Results and discussion}

The need for continuous professional training is determined by many factors, but the central place among them is occupied by the factor of the objectively existing relationship between $\mathrm{CPT}$ and the sector of the economy serving as a consumer of continuous professional training services. As such a sector of the economy, the work [8] considers production taking into account the genesis of intersubjective economic relationships without mentioning the sectoral aspect. At the same time, production is characterized by a generalized interpretation as a process of creating a product using production factors. This interpretation is fully consistent with construction production as an element of the species diversity of production activities. Taking this circumstance into consideration, it seems legitimate to consider the relationship and relationship between CPT and production as universal, but ideas about which can be transferred to a more specific species plane - from production as a whole to the sphere of construction production.

The genetic link between production and education is quite obvious, but its economic nature and features need clarification. This relationship is manifested primarily at the target level. In general, education and production are united by a systemic goal. This means that from a theoretical point of view, it is not possible to speak about the leading role of each of these elements, and hence its own goals. At the same time, these elements function autonomously and are divided institutionally, but between them numerous and diverse connections are formed. 
In this diversity, as noted in [8], it is possible to distinguish those connections that are determined by the decisive role of educational activity, and those that reflect the impact of production on education. The duality of ties determines the need to study the principles and methods of forming the goals of each of the subjects united by these ties - production and education, i.e., target relationships. When conducting such a study, it is important to be guided by the following setting - when approaching the methodological level, the target relationships should take the form of specific indicators, which in their composition and structure cannot contain contradictions, inconsistencies, imbalances, cannot but have such a quality as complementarity [10].

If we consider the impact of production on the educational process, it should be noted that this requirement is not met. In the regional management of continuous training (as well as at the level of public administration), CPT monitoring is carried out, using a base consisting of very specific indicators. The task of this monitoring is to adequately reflect the nature and degree of participation of lifelong education in the implementation of plans and programs for the socio-economic development of the regional (state) level through the training of relevant specialists.

The monitoring differentiates the areas of specialists (specialties) training, as well as the levels of training and qualifications. The table presents the generalized indicators [11] characterizing the state of the continuous training education system. At the same time, this table does not specify what CPT is being analyzed, but not the whole system of continuous training.

Table Generalized indicators characterizing the state of the continuous training system

\begin{tabular}{|c|l|c|}
\hline No. & \multicolumn{1}{|c|}{ Monitoring unit } & \multicolumn{1}{c|}{ Monitoring indicators } \\
\hline 1 & $\begin{array}{l}\text { Confirmation of the } \\
\text { possibility of training a } \\
\text { citizen at a certain } \\
\text { level of education }\end{array}$ & $\begin{array}{l}\text { - The number of persons with a certificate of } \\
\text { education, incl. by level of education } \\
\text { - The number of persons in need of training } \\
\text { (willing to undergo training), incl. by levels, } \\
\text { directions and specialties }\end{array}$ \\
\hline 2 & $\begin{array}{l}\text { Choice of specialty } \\
\text { and / or direction of } \\
\text { study }\end{array}$ & $\begin{array}{l}\text { - The number of persons applying for admission (by } \\
\text { levels, directions and specialties) }\end{array}$ \\
\hline 3 & $\begin{array}{l}\text { Training } \\
\text { (implementation of the } \\
\text { learning process) }\end{array}$ & $\begin{array}{l}\text { - The number of students (by levels, directions and } \\
\text { specialties) } \\
\text { - The number of places in educational institutions } \\
\text { (by levels, directions and specialties) } \\
\text { - Condition of educational places (material base, } \\
\text { personnel potential of educational institutions) }\end{array}$ \\
\hline 4 & $\begin{array}{l}\text { Choosing a trajectory } \\
\text { for completing training }\end{array}$ & $\begin{array}{l}\text { - The number of persons who chose a job upon } \\
\text { completion of training (by levels) } \\
\text { - Areas of activity in which persons who have } \\
\text { completed training enter (by levels, directions and } \\
\text { specialties) }\end{array}$ \\
\hline 5 & $\begin{array}{l}\text { - The number of persons who chose to continue their } \\
\text { studies (by levels, areas and specialties) }\end{array}$ \\
\hline
\end{tabular}

Analyzing the indicators and parameters presented in the Table, it is easy to see that they generally reflect the state of continuous professional education and can serve as its indicator. On their basis, important information can be formed that reflects the dynamics CPT, but the processes in the bundle "need for specialists - CPT" the shown indicators do not reflect. However, these needs are due to the development of regional production 
(production of goods and services) and can be outlined quite definitely. The needs for specialists of a certain profile, qualification level, and areas of training can be clearly recorded. These needs, and most importantly the degree of compliance of the current system with them CPT and should be reflected in monitoring [12]. The established practice of monitoring does not allow either to reflect the needs, or to characterize the degree of their satisfaction by CPT forces and, moreover, reflect the prospects for the development of this need.

It seems obvious, in this regard, the need to reformat the monitoring used in CPT practice. In the process of such reformatting, it is necessary:

- to ensure the analysis of the regional production (more precisely, the regional socioeconomic complex) needs in personnel of specialists of various profiles, qualifications, level of training;

- to form a methodology for this analysis, requirements for the composition and structure of the analyzed indicators, for the information database;

- to develop recommendations for forecasting the needs of regional production in professional personnel;

- - to form a system of requirements for CPT, adherence to which will ultimately ensure a balance between the needs for specialists and the results of continuous professional education.

If we consider the opposite effect - education on production, it is possible to replace the presence of a qualitatively different process. The work [8] investigated the situation in which the priority of the goals of education is fixed in comparison with the goals due to the development of production. The objectivity of such a priority is explained by the presence of a person's natural need for education and self-development throughout his entire working life.

The implementation of production goals is carried out in the process of meeting the needs of participants in the educational process, subject to the subsequent recognition of the results provided by this process in production activities. Participants in the educational process in this case perform the role of the consumer of educational services. These goals belong to the category of internal ones, characteristic of individuals as participants in the educational process. The needs of production, respectively, are reflected in external purposes [13].

To achieve a balance between the needs of production and the needs of a person participating in the education process, which ensures (along with other factors) the development of production, it is necessary for consumers of educational services to perceive external goals as internal, i.e., achieving target balance [14]. Monitoring CPT, in the algorithm, which is reflected using the materials presented in the table, to some extent is able to characterize the effect of education on production.

The duality of monitoring continuous professional training, its ability to characterize the same situation from different positions and taking into account different priorities allows us to formulate several important theses that should be taken into account when forming managerial decisions in the field CPT. The first of them is the features of the potential CPT. This potential is aimed both at ensuring the production process and the needs of a person - a participant in production. This means that during its implementation, conditions to achieve a synergistic effect are created, for example, due to the consistency of the tasks solved by the subjects CPT, with the exception of organizational contradictions between them, opportunities for developing coordinated strategic decisions, etc.

The second important thesis is the presence of a need for continuous professional training in any socio-economic conditions, i.e., in fact, the constancy of this need. This feature of the system CPT in its subjective structure determines the need for constant marketing research, especially in terms of researching the needs and demand for 
educational services provided by organizations that are the part of the continuous professional training system [15]. Marketing research (taking into account the noted duality $\mathrm{CPT}$ ) becomes a key function among the management functions implemented in organizations belonging to CPT.

It cannot but replace the fact that there are necessary objective prerequisites for conducting a study of this kind, namely, the monitoring itself. To provide CPT marketing orientation monitoring it is necessary to supplement the set of indicators and parameters used with marketing characteristics. It seems that the top-priority management action should be the addition, and in some cases the restructuring of the information base CPT, its reorientation towards the study of demand, the competitive environment, and other factors affecting the development of continuous professional training.

The third thesis is to provide opportunities for adjusting management mechanisms CPT, and not only strategic, based, in particular, on trends identified in the course of constant marketing research, but also tactical (and even operational), which are based on the identified relationships, observed not only in their duality, but also in dynamics [16].

\section{Conclusion}

Summarizing the above-said, it should be emphasized that the presented characteristics of the relationships under consideration were made using the method of qualitative analysis, i.e., focuses on the description of the properties of relationships and in this sense has some abstraction. When it is adapted to the conditions of construction production, no fundamental changes in the characteristics of relationships are found (due to the unity of the methodology of intersubjective interactions). But specificity is manifested in the process of implementing relationships and forming mechanisms of interaction between CPT and the manufacturing and construction sector. These include:

- wide differentiation of requirements for specialists of various profiles and skill levels;

- changes in the demand for labor resources observed in the production and construction sector (due to the complication of production and construction technologies), caused by increased requirements for the quality of training;

- the projected increase in demand for specialists of the highest qualifications as the crisis in the construction industry is overcome against the background of a stronger understanding of the key role in the CPT professional community in the human resources development;

- the presence of a generally formed system of continuous professional training in the production and construction sector, which, after appropriate modernization, can reach a qualitatively different level of consistency with the actual and predicted needs for specialists and labor resources.

These features require in-depth substantive consideration in the formation of management decisions on the effective implementation of the relationship between CPT and the manufacturing and construction sector.

\section{References}

1. M. Ivanova et al, MATEC Web of Conf. 170, 01094 (2018)

2. O. Egorova et al, IOP Conf. Ser.: Mater. Sci. Eng. 698, 077029 (2019) DOI: 10.1088 / 1757-899X / 698/7/077029

3. E. Trushkovskaya et al, IOP Conf. Ser.: Mater. Sci. Eng. 753, 032044 (2020) DOI: $10.1088 / 1757-899 X / 753 / 3 / 032044$ 
4. L. G. Selyutina, Innovative approach to managerial decision-making in construction business, Materials Science Forum 931, 1113-1117 (2018)

5. L. Egorova et al, IOP Conf. Ser.: Mater. Sci. Eng. 687, 044005 (2019) DOI: $10.1088 / 1757-899 \mathrm{X} / 687 / 4 / 044005$

6. Rybnov E et al, E3S Web of Conferences 217, 11010 (2020) DOI: $10.1051 / \mathrm{e} 3$ sconf $/ 202021711010$

7. K. Hartley et al, Thinking Skills and Creativity 22, 142 (2016)

8. N. A. Lobanov, V. N. Skvortsov, Lifelong learning: Continuous Education for Sustainable Development. Proceedings of the 14th International Conference 572 (St. Petersburg: Pushkin LSU), (2016)

9. T. Lomakina, Directory of the head of an educational institution 10 (106), 55 (2015)

10. T. Maleeva et al, IOP Conf. Ser.: Mater. Sci. Eng. 687, 044002 (2019) DOI: 10.1088 / 1757-899X / 687/4/044002

11. Yakhin Yu.A. et al, Life-long learning monitoring: governance tool and sociological aspects (MAKS-Press, Moscow, 2006)

12. E. Pesotskaya et al, IOP Conf. Ser.: Mater. Sci. Eng. 962, 022082 (2020) DOI: $10.1088 / 1757-899 X / 962 / 2 / 022082$

13. N. Frolova, et al, E3S Web of Conferences 97, 06003 (2019) DOI: $10.1051 /$ e3sconf/20199706003

14. L. Selyutina, Research result. Business and Service Technologies 4(4), 34 (2018)

15. V. Borodunova et al, KANT 4 (37), 191 (2020)

16. Hakimov A et al, AEBMR 157, 180 (2020) DOI: 10.2991/aebmr.k.201215.038 